\title{
Knowledge of CT exposure parameters among Norwegian student radiographers
}

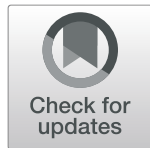

Sundaran Kada(1)

\begin{abstract}
Background: Improvements in the competency levels of student radiographers in computed tomography examinations $(C T)$ are important due to the increasing number of these examinations being undertaken in imaging departments. The present study assesses the knowledge of student radiographers regarding $\mathrm{CT}$ exposure parameters.

Methods: The level of knowledge related to $C T$ exposure parameters was evaluated using a twenty-one-item questionnaire that was distributed to final-year student radiographers. The questionnaire consisted of questions around CT exposure parameters and either allowed respondents to answer "true," or "false" or choose a response from a range of responses where only one answer was correct. Correct answers were given one mark, while no mark was given for an incorrect answer. The score out of possible 21 was converted to a percentage, with a higher percentage signifying greater knowledge.

Results: Seventy-two students completed and returned the questionnaire, resulting in a $71 \%$ response rate. The mean score was 53\%. Only 33\% of students correctly identified that kilovoltage peak (kVp) should be increased when patients have metallic implants, and milliampere seconds (mAs) should be increased as body part thickness increases. No one answered all the questions correctly. There was no significant knowledge difference between students who had CT facilities on campus and those that did not.
\end{abstract}

Conclusion: Overall, student radiographers' knowledge of CT exposure parameters was reported to be satisfactory.

Keywords: CT exposure parameters, Optimization, Radiation dose, Image quality, Student radiographers, Survey

\section{Background}

Developments in the technical aspects of computed tomography $(\mathrm{CT})$ technology, such as multidetector CT, iterative reconstruction algorithms, and dual-energy $\mathrm{CT}$, have resulted in increased scan speed and improved image quality $[1,2]$. This progress has resulted in a twofold increase in the use of CT examinations in the clinical environment over the past three decades [3]. CT is the most commonly used imaging modality in Norway [4], and its use doubled (11-21\%) from 2002 to 2008 [5]. CT examinations account for about $20 \%$ of all radiological

Correspondence: sundaran.kada@hvl.no

Faculty of Health and Social Sciences, Western Norway University of Applied Sciences, Post Box 7030, 5020 Bergen, Norway examinations in Norway and has the highest use of CT procedures among Nordic countries [6]. CT scans remain popular due to their capabilities [7], despite contributing significantly to ionizing radiation exposure for medical use. In fact, CT is the greatest source of exposure for the United States population, contributing to almost one-half of total radiation exposure for medical use $[8,9]$ and accounting for almost $60 \%$ of the radiation exposure from imaging modalities in western countries [10]. In Norway, CT examinations contributed to $66 \%$ of the total radiation dose received due to medical examinations in 2002 rising to $79 \%$ in 2008 [5]. It is estimated three new cases of cancer occur annually in Norway due to CT examinations [11]. Therefore the 'as low as reasonably achievable' (ALARA) principle must be practiced to ensure that the

C C The Author(s). 2020 Open Access This article is licensed under a Creative Commons Attribution 4.0 International License, which permits use, sharing, adaptation, distribution and reproduction in any medium or format, as long as you give appropriate credit to the original author(s) and the source, provide a link to the Creative Commons licence, and indicate if changes were made. The images or other third party material in this article are included in the article's Creative Commons licence, unless indicated otherwise in a credit line to the material. If material is not included in the article's Creative Commons licence and your intended use is not permitted by statutory regulation or exceeds the permitted use, you will need to obtain permission directly from the copyright holder. To view a copy of this licence, visit http://creativecommons.org/licenses/by/4.0/ The Creative Commons Public Domain Dedication waiver (http://creativecommons.org/publicdomain/zero/1.0/) applies to the data made available in this article, unless otherwise stated in a credit line to the data. 
benefits from undertaking the scan are always greater than the possible risks [12].

There are six radiography schools in Norway. Radiography education in Norway involves a three-year degree program and one-third of this time is spent in clinical practice. Teaching of radiography students is undertaken by lecturers in the academic settings and by supervising clinical radiographers in the clinical settings. On average $20 \mathrm{~h}$ of lectures are provided on CT related topics in the university setting, including $2-4 \mathrm{~h}$ of lectures specifically related to exposure parameters. In addition, all students must have a minimum of 5 weeks CT clinical placement in radiology departments during their study program. Theoretical competency is assessed via written examination during the first and second year, and clinical competence is assessed by a clinical supervising radiographer at the end of the students' clinical placement period. Only one of the universities that provides radiography education in Norway has CT machine in its skills laboratories (skills labs) on campus.

CT exposure parameters, such as kilovoltage peak $(\mathrm{kVp})$, milliampere seconds (mAs), pitch, slice thickness, automatic tube current modulation (ATCM), detector configuration, and reconstruction algorithms, control radiation dose and image quality [13]. There are several possible combinations of these parameters available that enables the radiographer to select a protocol that provides optimal image quality along with a reduced radiation dose. Some combinations can be manufacture specific, however, the standard settings and manufacturer recommendations may be designed for an average sized patient aimed at optimizing image quality rather than radiation dose [14]. CT dose reduction requires a combination of strategies including, optimization of scanning protocols, justification of CT use, decrease of unnecessary examinations, and better training and education for radiographers [15]. Dose optimization contributes to significant reduction in radiation dose to adults [15] and understanding CT exposure parameters is a prerequisite for dose optimization [16]. For example, any change in $\mathrm{kVp}$ affects the image noise, contrast and patient dose [17], mAs determines image noise and patient dose [18], ATCM reduces radiation dose by up to $25-$ $50 \%$ in children and adults $[19,20]$, and iterative reconstruction algorithms is reported to be a new era in CT optimization providing high quality images with $28-98 \%$ dose reduction [21]. Therefore, there is a need to understand the appropriate strategies to optimize CT examinations in order to comply with the ALARA principle. Once examinations are justified, radiographers select the best combination of imaging parameters for each individual patient to achieve sufficient image quality to provide a diagnosis with the lowest radiation dose to the patient. It is therefore necessary to have sound knowledge about CT exposure parameters and their effects on both image quality and radiation dose to develop an optimization protocol. A lack of understanding will therefore limit the potential for optimization [22]. Studies have described radiographers' self-reported competency on CT exposure parameters [23-25]. However, to the author's knowledge, no studies have been conducted nationally or internationally to assess student radiographers' level of knowledge of exposure parameters in CT. Accordingly, the present study assesses the knowledge of student radiographers' regarding CT exposure parameters. In addition, the study explores if there is an association between students' level of knowledge and the availability of a CT machine in the skills labs on campus. It is hypothesized that students generally have a good knowledge of CT exposure parameters and students with access to a CT machine on campus will have a higher level of knowledge than students who do not.

\section{Methods \\ Design and subjects}

This was a cross-sectional questionnaire-based study that was performed in Norway, which has a population of nearly 7 million people. Subjects were student radiographers in their final semester of the study program, prior to graduating in June 2019. Three of the five schools that have no CT on campus were randomly selected to participate in this study. All students from the one school that has CT equipment on campus were also included in this study. Therefore, students from four schools of radiography were invited to participate.

\section{Procedure}

Heads of the schools of radiography that were to be included in this study, were contacted to request their consent to participate. After approval, questionnaires with an information letter were sent to the study coordinators to distribute them, collect them at the end of a teaching session, and send them back to author. Students were reminded to complete the questionnaires based on their own knowledge and not to use books or other sources when completing the questionnaire. The information letter explained the aim of the project, providing a guarantee of confidentiality (with regard to personal information), emphasizing the voluntary nature of participation, and finally, notifying the participants that they could access the results of the study by contacting the author. Data was collected in March 2019. Verbal consent was taken.

\section{Sample}

A total of 72 final-year student radiographers from a possible sample of 101 participated (27 students from a 
possible sample of 32 from schools that have CT equipment and 45 students from a possible sample of 69 from schools that do not have CT equipment). At the time the study was conducted all students had undertaken their clinical placement in CT (a minimum of 5 weeks).

\section{Measures}

Knowledge related to CT exposure parameters was measured using the Norwegian translation (translated, translated back and retranslated) of the English version of the questionnaire. The English version of the questionnaire was developed specifically to measure knowledge levels on CT exposure parameters and published in earlier studies [23, 24]. However, these questionnaires were not validated. The Norwegian translation version of the questionnaire was piloted to ten subjects. Based on suitability and feedback from the pilot study, the Norwegian version of the questionnaire contains two sections (Appendix). The first section consists of demographic information (whether the university has its own CT machine on campus, the number of weeks undertaking CT clinical placement, and confidence in their knowledge about changing CT exposure parameters in relation to radiation dosage and image quality). The second section consists of twenty-one questions related to $\mathrm{CT}$ exposure parameters $(\mathrm{kVp}, \mathrm{mAs}, \mathrm{ATCM}$, pitch, slice thickness). The answers were measured using a two-point scale: "true/ false" or in a multiple-choice format where there is only one correct answer. Correct answers were given one mark, while no mark was given for an incorrect answer. Unanswered questions were scored as incorrect. The total score ranges are from 0 to 21 , which were converted to a percentage. The Norwegian association of higher education institutions description of valuation criteria [26] was used to explain the students' level of knowledge (Table 1). Students' scores were compared with this valuation criteria to assess level of knowledge.

\section{Ethical considerations}

The study followed the standard ethical guidelines for research conducted on students in Norway. Students were informed that participation was voluntary, and they were guaranteed anonymity and confidentiality. Approvals from the Medical Research Ethical Committee and the Norwegian Social Science Data Services were not required for this study.

\section{Statistical analysis}

Descriptive statistics (frequency, percentage) are presented for demographic characteristics and mean, confidence interval $(\mathrm{CI})$ for the summary score. Independent t-tests were conducted to compare the knowledge scores between students with or without confidence in their knowledge of CT exposure parameters and between students with and without CT equipment on campus. The relationship between knowledge scores and the students' confidence in their knowledge was assessed using the Pearson correlation coefficient test. A $p$-value of less than 0.05 was considered to be statistically significant. Analyses were performed using the Statistical Package for the Social Sciences (SPSS), version 25.0.

\section{Results}

A total of 101 questionnaires were distributed, and 72 students returned the questionnaire, resulting in a $71 \%$ response rate. Demographic characteristics of student radiographers including whether the school has its own CT machine on campus, the number of weeks in CT clinical placement, and confidence with knowledge in changing CT parameters in relation to radiation dosage and image quality are shown in Table 2.

The summary scores for the students' knowledge was $53 \%$. Twenty-six students (36\%) answered more than $50 \%$ incorrect. Only 24 (33\%) correctly answered that $\mathrm{kVp}$ should be increased for patients with metallic implants and mAs should be increased as body part

Table 1 General description of valuation criteria

\begin{tabular}{lll}
\hline Symbol & Description & General, qualitative description of valuation criteria \\
\hline A & Excellent & $\begin{array}{l}\text { An excellent performance, clearly outstanding. The candidate demonstrates excellent judgement and a very high degree } \\
\text { of independent thinking }\end{array}$ \\
B & Very good & A very good performance. The candidate demonstrates sound judgement and a high degree of independent thinking \\
C & Good & $\begin{array}{l}\text { A good performance in most areas. The candidate demonstrates a reasonable degree of judgement and independent } \\
\text { thinking in the most important areas }\end{array}$ \\
D & Satisfactory & $\begin{array}{l}\text { A satisfactory performance, but with significant shortcomings. The candidate demonstrates a limited degree of } \\
\text { judgement and independent thinking }\end{array}$ \\
E & Sufficient & $\begin{array}{l}\text { A performance that meets the minimum criteria, but no more. The candidate demonstrates a very limited degree of } \\
\text { judgement and independent thinking }\end{array}$ \\
F & Fail & A performance that does not meet the minimum academic criteria. The candidate demonstrates an absence of both
\end{tabular}

Symbol A represents mark between 88 and 100\%, symbol B represents mark between 76 and $87 \%$, Symbol C represents mark between 64 and $75 \%$, symbol D represents mark between 52 and 63\%, symbol E represents mark between 40 and $51 \%$ and symbol $\mathrm{F}$ represents mark below $40 \%$ 
Table 2 Demographic characteristics of participants $(n=72)$

\begin{tabular}{ll}
\hline Variable & N (\%) \\
\hline CT on campus & $27(38)$ \\
Yes & $45(62)$ \\
No & \\
CT clinical placement & $26(36)$ \\
$1-5$ weeks & $42(59)$ \\
$6-10$ weeks & $3(4)$ \\
$11-15$ weeks & $1(1)$ \\
16-20 weeks & \\
Confidence with knowledge & $3(5)$ \\
Very confident & $32(44)$ \\
Moderately confident & $32(44)$ \\
Less confident & $5(7)$ \\
Not confident & \\
\hline
\end{tabular}

thickness increases. No one answered all the questions correctly. The students' responses to each of the questions are presented in Table 3.

No significant differences in knowledge scores were identified between students who reported being very/ moderately confident (mean score 57\%) and less/not confident in their knowledge (mean score 49\%, $p=$ 0.053) and between students from the school with CT equipment and schools without such equipment on campus (mean score $55 \%$ versus mean score $52 \%, p=$ 0.541) (Table 4). The Pearson correlation between students' levels of confidence in their knowledge and the CT exposure parameter knowledge score was $0.073(p=0.051)$.

\section{Discussion}

Overall, the current study indicates a satisfactory level of knowledge about CT exposure parameters (as measured by the mean score of 53\%). According to the Norwegian Association of higher education institutions valuation criteria, marks between 52 and 63\% indicates that performance is satisfactory, but with significant shortcomings; candidates demonstrate a limited degree of judgement and independent thinking [26]. The study findings are discouraging and raise concerns about knowledge levels related to CT exposure parameters among student radiographers prior to graduation. The title "radiographer" reflects the education and knowledge required to work safely in the field of diagnostic radiology. A possible explanation for the present findings could be that admission to radiography programs in

Table 3 Frequency distributions of responses to questionnaires $(n=72)$

\begin{tabular}{|c|c|c|}
\hline Questions & $\begin{array}{l}\text { True } \\
(\%)\end{array}$ & $\begin{array}{l}\text { False } \\
(\%)\end{array}$ \\
\hline 1. Reducing $\mathrm{kVp}$ would reduce the contrast resolution & $41(57)$ & $31(43)$ \\
\hline 2. Increasing $\mathrm{kVp}$ by $50 \%$ is equivalent to doubling the $\mathrm{mAs}$ & $39(54)$ & $33(46)$ \\
\hline 3. kVp should be increased with patients having metallic implants & $24(33)$ & $48(67)$ \\
\hline 4. Doubling the mAs doubles the dose & $55(76)$ & $17(24)$ \\
\hline 5. Reducing the $\mathrm{mAs}$ reduces the noise & $52(72)$ & $20(28)$ \\
\hline 6. mAs should be increased as the body part thickness increases & $24(33)$ & $48(67)$ \\
\hline 7. ATCM is affected by improper patient positioning & $51(71)$ & $21(29)$ \\
\hline 8. ATCM decreases patient dose & $49(68)$ & $23(32)$ \\
\hline 9. ATCM increases the dose to obese patients & $39(54)$ & $33(46)$ \\
\hline 10. Decreasing the pitch degrades image quality & $29(40)$ & $43(60)$ \\
\hline 11. Increasing the pitch decreases the dose & $38(53)$ & $34(47)$ \\
\hline 12. Increasing the slice thickness decreases the dose & $37(51)$ & $35(49)$ \\
\hline 13. Decreasing the slice thickness reduces partial volume artefact & $39(54)$ & $33(46)$ \\
\hline 14. Increasing mAs decreases noise & $57(79)$ & $15(21)$ \\
\hline 15. Increasing kVp decreases noise & $36(50)$ & $36(50)$ \\
\hline 16. Increasing slice thickness increases noise & $34(47)$ & $38(53)$ \\
\hline 17. Increasing pitch increases noise & $28(39)$ & $44(61)$ \\
\hline 18. A smoothing reconstruction kernel, increases the visualization of noise & $25(35)$ & $47(65)$ \\
\hline 19. Wider window settings, reduce the image contrast but also the visual perception of noise & $27(37)$ & $45(63)$ \\
\hline 20. Increasing the $\mathrm{kVp}$ from 120 to $140 \mathrm{kVp}$ causes an increase in CTDI values of: & $50(69)$ & $22(31)$ \\
\hline $\begin{array}{l}\text { 21. Which is the most informative index regarding the amount of dose that the patient would receive by the end of the } \\
\text { examination?? }\end{array}$ & $28(39)$ & $44(61)$ \\
\hline
\end{tabular}


Table $4 \mathrm{CT}$ exposure parameter knowledge scores

\begin{tabular}{lll}
\hline Characteristic & Mean score (95\% Cl) & P-value \\
\hline Total group & $53 \%(41-65 \%)$ & \\
Study place & & 0.541 \\
CT on campus & $55 \%(43-67 \%)$ & \\
No CT on campus & $52 \%(40-64 \%)$ & 0.053 \\
Confidence of knowledge & & \\
Very/moderately confident & $57 \%(45-69 \%)$ & \\
Less/not confident & $49 \%(37-61 \%)$ & \\
\hline
\end{tabular}

Norway do not require high levels of knowledge in science subjects such as physics, mathematics, or chemistry. In the author's experience, most students who lack this prerequisite knowledge find it difficult to cope with science-related subjects such as radiation physics and CT. Another possible explanation could be that supervising radiographers have not received specific training for their role. It has been indicated that training in supervision is a requirement for supervising staff [27]. Supervision is defined as, 'the provision of guidance and feedback on matters of personal, professional and educational development in the context of a trainee's experience of providing safe and appropriate patient care' [28]. The supervising staff need to be clinically competent, knowledgeable and have good teaching and interpersonal skills to impart their knowledge effectively [29]. Furthermore, a student radiographer's clinical practice takes place in a frequently busy, unpredictable context. Clinical staff are often distracted with their daily work schedule and may not have the time to allocate to teaching, which in turn hinders a student's clinical competency [30]. A strong support is therefore required to enable effective and safe progression of a student's learning in the clinical setting [31].

The finding that there was no significant difference in knowledge scores between those students that have CT equipment on campus and those that do not is dramatic and surprising. One might expect that the students from the school with a CT machine on campus would be more exposed to practical assignments where students develop protocols with various combinations of parameters, which would help solidify their theoretical and clinical knowledge. This study finding is inconsistent with earlier studies that identified more knowledge when skills labs are available on campus among medical students [32-34] and student radiographers [35]. Skills labs help students to bridge the gap between knowledge and practice and makes theoretical teaching "come alive" [36]. They also ensure that students acquire the necessary techniques and are properly assessed before practicing on real patient [37]. There are certain skills that cannot be practiced in real life-situations due to ethical reason. For example, training on real patients is not possible due to the harmful ionizing radiation involved. Clinical skills labs solve this problem by providing a safe environment for students to learn, practice and be observed performing skills in a simulated environment, thereby alleviating the risks involved in direct patient exposure [38]. There is no explanation for the present study finding. However, a potential reason could be that little time is allocated in skills labs for practical assignments or there is a lack of feedback from academic staff. In an internal evaluation, students reported a lack of feedback from academic staff for assignments. It has been demonstrated that feedback enhances trainees to reflect upon their actions, realize errors and to individually evaluate their learning progress [39]. As the subjects are future registered radiographers, they should be taught about CT exposure parameters so that they can effectively determine the examination protocol to be used during CT procedures to avoid excessive radiation dose to patients.

The study findings identify a lack of theoretical knowledge around the effects of CT exposure parameters on image quality and radiation dose. Therefore, the content of this theoretical study should be reviewed and updated. It is also recommended that radiography schools in Norway provide additional physics and math's classes prior to CT related lectures and more case-based learning methods to improve students' performance in this area of practice. Combined practical and theoretical knowledge leads to better outcomes in the teaching field and empowers more self-confidence of those working in the profession. Such a combined approach to teaching would enable learners to work more competently and be prepared to take responsibility in their future careers [40]. Knowledgeable and well-trained students play an important role in the creation of a positive radiation safety culture. Medical imaging, which is becoming increasingly complex and has an important impact on diagnosis [41], is an excellent example of a field in which competence is required [42-44].

\section{Strengths and limitations}

Four out of six (67\%) radiography schools in Norway participated in the current study, with a response rate of $71 \%$. Therefore, this study concludes that the sample group is representative, which means that the results can be generalized as being indicative of the general knowledge of final-year student radiographers in Norway. A possible limitation of this study is that the questionnaires were distributed by study coordinators, which might have affected the degree to which participants were informed about the study, even though information letters were sent along with the questionnaires. Furthermore, there is no confirmation that the missing 
questionnaires were distributed or whether student radiographers were present during the time of distribution.

\section{Conclusion}

The present study has shown that student radiographers have a satisfactory knowledge that demonstrates a very limited degree of judgement and independent thinking. Additionally, the student radiographers from the school with a CT machine on campus are not as knowledgeable about CT exposure parameters as might be expected.

\section{Implications for practices}

The educational curriculum needs to be revised and updated with the importance of knowledge about CT exposure parameters emphasized during lectures. Radiographers that supervise students should be provided with specific training on the supervision of students and their role in this. Supervising radiographers should increase the amount of attention they give to these areas by providing specific knowledge around CT exposure parameters during mentorship and supervision. All radiography schools must strive to have skills labs with CT machines and more experimental assignments on phantoms should be conducted, to increase understanding of exposure parameters. It is essential that students are educated and supported in the development of their skills and knowledge in this area because of the increasing number of CT examinations globally and the risks associated with $\mathrm{CT}$ examinations.

Further studies are required to determine the benefits of having a CT machine on campus and to understand why students do not think these opportunities help them develop judgement and decision-making skills.

\section{Supplementary information}

Supplementary information accompanies this paper at https://doi.org/10. 1186/s12909-020-02233-y.

\section{Additional file 1.}

\section{Abbreviations}

CT: Computed tomography; ALARA: As low as reasonably achievable; kVp: Kilovoltage peak; mAs: Milliampere seconds; ATCM: Automatic tube current modulation; SPSS: Statistical package for the social sciences;

$\mathrm{Cl}$ : Confidence interval

\section{Acknowledgments}

The author thanks Sandra H Hovland and Sofia M Kolbensen for data collection, all the teachers in charge for distributing and collecting the questionnaire, and all the participating student radiographers. The author also thanks Dr. Lisa Booth for English correction.

\section{Author's contributions}

SK was the author in writing the manuscript. The author(s) read and approved the final manuscript.
Funding

Not applicable.

Availability of data and materials

The datasets used and/or analyzed during the current study are available from the corresponding author on reasonable request.

\section{Ethics approval and consent to participate}

The study followed the standard ethical guidelines for research conducted on students in Norway. The heads of participating schools granted permission for their schools to be involved in this study. All the participants were provided detailed information about the purpose of the study so that they could make informed decisions regarding participation. They were assured that the participation was voluntary, and they were guaranteed anonymity and confidentiality Approvals from the Medical Research Ethical Committee and the Norwegian Social Science Data Services were not required for this study.

Coordinators (Eli B Eikefjord, Western Norway University of Applied sciences; Linda Hafskjold, University of South-Eastern Norway; Astrid Berntsen, Norwegian University of Science and Technology; and Cato Johansen, UiT The Arctic University of Norway) from participating institutions approved this study. The study participants were informed about their consent orally and in writing.

\section{Consent for publication}

Not applicable.

\section{Competing interests}

The author declares that there are no competing interests.

Received: 14 February 2020 Accepted: 9 September 2020

Published online: 14 September 2020

\section{References}

1. Pelc NJ. Recent and future directions in CT imaging. Ann Biomed Eng. 2014; 42(2):260-8

2. United Nations Scientific Committee on the Effects of Atomic Radiation Sources and effects of ionizing radiation: UNSCEAR. Report to the general assembly, with scientific annexes. New York: United Nations; 2008.

3. Bellolio MF, Bellew SD, Sangaralingham LR, et al. Access to primary care and computed tomography use in the emergency department. BMC Health Serv Res. 2018;18(1):154. https://doi.org/10.1186/s12913-018-2958-4.

4. Helsedirektoratet. Nasjonal faglig retningslinje for bildediagnostikk ved ikketraumatiske muskel- og skjelettlidelser. Anbefalinger for primærhelsetjenesten 2014 [Norwegian]. Available: https://www. helsebiblioteket.no/retningslinjer/bildediagnostikk/generelt-ombildediagnostikk/stråling.

5. Almen A, Friberg EG, Widmark A, Olderud HM. Radiologiske undersøkelser i Norge per 2008. Trender I undersøkelsesfrekvens og stråledoser til befolkningen. Strålevern Rapport 2010:12. Østerås: [Norwegian] http://www. nrpa.no/dav/dc3ba89a7a.pdf. Accessed 30 Oct 2019.

6. Norwegian Radiation and Nuclear Safety Authority. Trendene i antall datatomografi (CT) undersøkelser per 1000 innbyggere i de nordiske landene fra 1993 til 2010. 2012 [Norwegian]. Available: https://www.dsa.no/ nyheter/88889/oekt-ct-bruk-foerer-til-bekymring-i-de-nordiske-landene). Accessed 20 Jan 2020

7. Lee TY, Chhem RK. Impact of new technologies on dose reduction in CT. Eur J Radiol. 2010;76(1):28-35. https://doi.org/10.1016/j.ejrad.2010.06.036.

8. Wall BF. Ionizing radiation exposure of the population of the United States: NCRP Report No.160 Radiat Prot Dosim. 2009;136(2):136 -138 doi: https:// doi.org/10.1093/rpd/ncp162.

9. Brenner DJ, Hall EJ. Computed tomography_an increasing source of radiation exposure. N Engl J Med. 2007;357(22):2277-84.

10. Verdun FR, Racine $D, O t t ~ J G$, et.al. Image quality in $C T$ : from physical measurements to model observers. Phys Med2015; 31(8):823-843.

11. Wisborg T. Overbruk av CT ved traumemottak? Tidsskr Nor Legeforen. 2019; 5. https://doi.org/10.4045/tidsskr.19.0038.

12. Valentin J. Managing patient dose in multi-detector computed tomography (MDCT). ICRP publication 102. Ann ICRP. 2007;37(1):1-79. 
13. Raman SP, Mahesh M, Blasko RV, et al. CT scan parameters and radiation dose: practical advice for radiologists. J Am Coll Radiol. 2013;10(11):840-6. https://doi.org/10.1016/j.jacr.2013.05.032.

14. Amis ES Jr, Butler PF, Applegate K, et al. American College of radiology white paper on radiation dose in medicine. J Am Coll Radiol. 2007;4(5):27284. https://doi.org/10.1016/j.jacr.2007.03.002.

15. Sakhnini A. CT radiation dose optimization and reduction for routine head, chest and abdominal CT examinations. Radiol Diagn Imaging. 2017;2(1):1-4. https://doi.org/10.15761/RDI.1000120.

16. Goo HW. CT radiation dose optimization and estimation: an update for radiologists. Korean J Radiol. 2012;13(1):1-11. https://doi.org/10.3348/kjr. 2012.13.1.1.

17. Hsieh J. Computed tomography: principles, design, artifacts, and recent advances. Bellingham: SPIE; 2009.

18. Al Mohiy H, Sim J, Seeram E, Davidson R. Differences between Saudi Arabian and Australian radiographers' knowledge and attitudes about paediatric CT doses. Radiographer. 2011;58:21-7.

19. Goo HW. Individualized volume CT dose index determined by crosssectional area and mean density of the body to achieve uniform image noise of contrast-enhanced pediatric chest CT obtained at variable kV levels and with combined tube current modulation. Pediatr Radiol. 2011:41:83947.

20. Greess H, Wolf H, Baum U, Lell M, Pirkl M, Kalender W, Bautz WA. Dose reduction in computed tomography by attenuation-based on-line modulation of tube current: evaluation of six anatomical regions. Eur Radiol. 2000;10:391-994.

21. Kordolaimi SD, Argentos S, Pantos I, Kelekis NL, Efstathopoulos EP. A new era in computed tomographic dose optimization: the impact of iterative reconstruction on image quality and radiation dose. J Comput Assist Tomogr. 2013;37:924-31.

22. Karim MKA, Hashim S, Bradley DA, Bahruddin NA, Ang WC, Ne S. Assessment of knowledge and awareness among radiology personnel regarding current computed tomography technology and radiation dose. J Phys: Conf Ser. 2016;694:012031. https://doi.org/10.1088/1742-6596/694/1/ 012031

23. Rawashdeh M, McEntee MF, Zaitoun M, et al. Knowledge and practice of computed tomography exposure parameters amongst radiographers in Jordan. Comput Biol Med. 2018;102:132-7. https://doi.org/10.1016/j. compbiomed.2018.09.020.

24. Foley SJ, Evanoff MG, Rainford LA. A questionnaire survey reviewing radiologists' and clinical specialist radiographers' knowledge of CT exposure parameters. Insights Imaging. 2013;4:637-46. https://doi.org/10.1007/s13244013-0282-4.

25. Farshid M, Mozafar N, Zahra F, et al. Evaluation of radiographers' and CT technologists' knowledge regarding CT exposure parameters. Pol J Med Phys Eng. 2019;25(1):43-50.

26. The Norwegian association of higher education institutions. General qualitative description of valuation criteria. 2011. https://www.uhr.no/_f/p1/ i4bfb251a-5e7c-4e34-916b-85478c61a800/karaktersystemet_generelle_ kvalitative_beskrivelser.pdf.

27. Geers-van EA, Gemeren S, Henner A, Kukkes T, Pronk-Larive D, Rainford L, McNulty JP. Clinical radiography education across Europe. Radiography. 2017:23(1):S7-S15.

28. Kilminster $S \&$ Cottrell D, Grant J, jolly B. AMEE guide no.27: effective educational and clinical supervision. Med Teach 2007;29(1):2-19 doi: https:// doi.org/10.1080/01421590701210907.

29. Ditchfield MR \& Fink AM. Role of supervision in radiology practice. Australas radiol.2003;47(3):1-3 doi: https://doi.org/10.1046/j.1440-1673. 2003.01123. x.

30. Dhakal AK, Dhakal S. Clinical skills lab: a need in Nepalese medical school. J Patan Acad Health Sci. 2014;1(1):49-51.

31. Thompson A, Smythe L, Jones M. Partnership for clinical learning: a collaborative initiative to support medical imaging technology students and their supervisors. Radiography. 2016;22:e118-24.

32. Upadhayay N. Clinical training in medical students during preclinical years in the skill lab. Adv Med Educ Pract. 2017;8:189-94.

33. Al-Elq AH. Medicine and clinical skills laboratories. J Family Community Med. 2007;14(2):59-63.

34. Hashim R, Qamar K, Khan MA, Rehman S. Role of skill laboratory training in medical education - students' perspective. J Coll Physicians Surg Pak. 2016; 26(3):195-8
35. Kong A, Hodgson Y, Druva R. The role of simulation in developing clinical knowledge and increasing clinical confidence in first-year radiography students. Focus on health professional education: a multi-disciplinary journal 2015; 16 (3): 29-44.

36. Bligh J. The clinical skills unit. Postgrad Med J. 1995;71:730-2.

37. Rush S, Ooms A, Marks-Maren D, Firth T. Students' perceptions of practice assessment in the skills laboratory: an evaluation study of OSCAs with immediate feedback. Nurse Educ Pract. 2014;14:627-34. https://doi.org/10 1016/j.nepr.2014.06.008.

38. Bugaj TJ, Nikendei C. Practical clinical training in skills labs: theory and practice. GMS J Med Educ. 2016;33(4):1-21. https://doi.org/10.3205/ zma001062.

39. Issenberg SB, McGaghie WC, Petrusa ER, Lee Gordon D, Scalese RJ. Features and uses of high-fidelity medical simulations that lead to effective learning: a BEME systematic review. Med Teach. 2005;27(1):10-28. https://doi.org/10. 1080/01421590500046924

40. Farajollahi AR, Fouladi DF, Ghojazadeh M, et al. Radiographers' professional knowledge regarding parameters and safety issues in plain radiography: a questionnaire survey. Br J Radiol. 2014;87(1040):20140090. https://doi.org/10. 1259/bjr.20140090.

41. Brealey S, Scally AJ, Thomas NB. Review article: methodological standards in radiographer plain film reading performance studies. Br J Radiol. 2002;75:107.

42. Aspelin P. Toward providing effective, efficient, and equitable care: how much care can we afford? J Am Coll Radiol. 2011;8:828-9. https://doi.org/10. 1016/j.jacr.2011.08.007.

43. Andersson BT, Christensson L, Jakobsson U, et al. Radiographers' selfassessed level and use of competencies-a national survey. Insights Imaging. 2012;3:635-45. https://doi.org/10.1007/s13244-012-0194-8.

44. Eklund $\mathrm{K}$, Klefsgard $\mathrm{R}$, Ivarsson $\mathrm{B}$, et al. Positive experience of a mobile radiography service in nursing homes. Gerontology. 2012;58:107-11. https:// doi.org/10.1159/000329452.

\section{Publisher's Note}

Springer Nature remains neutral with regard to jurisdictional claims in published maps and institutional affiliations.
Ready to submit your research? Choose BMC and benefit from:

- fast, convenient online submission

- thorough peer review by experienced researchers in your field

- rapid publication on acceptance

- support for research data, including large and complex data types

- gold Open Access which fosters wider collaboration and increased citations

- maximum visibility for your research: over $100 \mathrm{M}$ website views per year

At $\mathrm{BMC}$, research is always in progress.

Learn more biomedcentral.com/submissions 